\title{
La proyección de la imagen de Benedicto XVI por parte del diario El País: una reflexión sobre ética periodística a la luz de la ética empresarial
}

The Projection of Benedict XVI's Image by the Newspaper El País: a Reflection on Journalistic Ethics in the Light of Business Ethics

\section{CAROLA Minguet CIVERA \\ Universidad Católica de Valencia San Vicente Mártir ORCID: 0000-0002-9367-5132 \\ carola.minguet@ucv.es}

Resumen: La ética periodística y la ética empresarial tienen más en común de lo que se ha reconocido tradicionalmente. Así, a partir de una muestra del tratamiento informativo realizado por un diario generalista -referente en España- al pontificado de Benedicto XVI, se proponen algunos de los retos a los que debe atender la primera, considerando el examen de las ideas ofrecidas por quienes operan desde la perspectiva de las organizaciones.

Palabras clave: Ética Empresarial, Ética Periodística, Servicio Público, Meaningful Work, Periodismo Religioso, Benedicto XVI.

\begin{abstract}
Journalistic ethics and business ethics have more in common than has been traditionally recognized. Thus, based on a sample of the informative treatment of Benedict XVI's pontificate by a generalist newspaper-a reference newspaper in Spain-, some of the challenges that the former should address are proposed, considering the examination of the ideas offered by those who operate from the perspective of organizations.
\end{abstract}

Key words: Business Ethics, Journalistic Ethics, Public Service, Meaningful Work, Religious Journalism, Benedict XVI. 


\section{INTRODUCCIÓN}

La investigación sobre la ética en la comunicación "es un tapiz complejo que se va conformando con viejas y nuevas fibras"1. Como señalan García de Torres y Farmer, recientemente se han sumado trabajos sobre el impacto de las nuevas tecnologías y el periodismo en red $^{2}$, la protección de datos y la privacidad $^{3}$, la valoración de las audiencias ${ }^{4}$, así como sobre el contexto empresarial y el papel de la gestión pública ${ }^{5}$.

Estos análisis se entrelazan con otros centrados en prácticas y agendas guiadas por el beneficio económico o el interés ideológico ${ }^{6}$-que, además, no favorecen la inclusión de públicos vulnerables ni el tratamiento adecuado de determinadas áreas temáticas-, las expectativas fallidas de la opinión pública respecto de los medios ${ }^{7}$, la crisis de identidad del periodista ${ }^{8}$ o la influencia de entidades y actitudes profesionales en la información ${ }^{9}$.

Por otro lado, la producción científica incluye investigaciones referidas a la deontología profesional en el sector y la regulación externa de las empresas $^{10}$, así como propuestas de promoción de contenidos éticos en las facultades de Ciencias de la Información, congresos y publicaciones científicas ${ }^{11}$.

Dichos estudios ponen en valor los progresos conseguidos en las últimas décadas e identifican los puntos cruciales a los que debe seguir atendiendo la investigación en este sentido. Si bien el campo es amplísimo, se puede encontrar un denominador común en la literatura, y es que radica en el imperativo ético que subyace al sector de los mass media por su condición de servicio público, de atención al bien común ${ }^{12}$.

1 García de Torres, E. y Farmer, Y. (2017), p. 154.

2 Núñez, M. (2011); Singer, J. B. (2008).

3 Baruh, L. y Popescu, M. (2017); Pence, H. E. (2015); Youm, H. Y. y Park, A. (2016).

4 Craft, S.; Vos, T. P. y Wolfgang J. D. (2015); Örnebring, H. (2013); Van der Wurff, R. y Shoenbach, K. (2014).

5 Bañón, A.; Guillén, M. y Ramos, N. (2011); Chillón, J. M. (2011); Djerf-Pierre M.; Ekström, M. y Johansson, B. (2013); Maciá-Barber, C. (2014).

6 Blázquez, N. (2002); Santín, M. (2012).

7 Gil de Zúñiga, H. y Hinsley, A. (2013); Kovac, B. y Rosenstiel, T. (2003); Lee, A. M. y Chyi, H. I. (2014); Parés-Maicas, M. (1995); Urban, J. y Schweiger, W. (2014).

8 Figueras, M.; Mauri, M.; Alsius, S. y Salgado F. (2012).

9 Martínez Albertos, J. M. (2005); McQuail, D. (1992).

10 Aznar, H. (2005); Escobar, G. (2002); Lambeth, E. B. (1992).

11 Eberholst, M. K.; Hartley, J. M. y Olsen, M. B. (2016); Wyatt, W. N. (ed.) (2014).

12 Merrill, J. C. (1997); Meyers, C. (2010); Rosenstiel, T. y McBride, K. (eds.) (2013); Sanders, K. (2003); Sinova, J. (2003); Tremblay, G. (2014); Ward, S. J. A. (2010). 
Este punto de encuentro enlaza, asimismo, con el fundamento de la ética empresarial: si bien no cabe exigir a las organizaciones una condición moral (pues ésta se refiere al comportamiento personal), sí conviene exigirles responsabilidades que pueden situarse en los aledaños de la ética. Es decir, aunque se entiende que no existe una conciencia colectiva, y que sólo metafóricamente se puede apuntar que una empresa es o no es ética, sí puede atribuirse a las entidades obligaciones que anidan en los cimientos de esta disciplina ${ }^{13}$.

Así, estas páginas asumen que, también en el sector de los medios de comunicación, la ética profesional se entrecruza con la ética en las organizaciones, de modo que la ética empresarial y la ética periodística parecen tener una mayor sintonía de lo que se ha reconocido tradicionalmente ${ }^{14}$.

Para profundizar en ello, se presenta un estudio sobre praxis periodística en un diario generalista referente en España a la hora de informar sobre la Iglesia católica. Las razones que fundamentan esta elección descansan en dos aspectos. En primer lugar, se considera que un examen de la prensa escrita permite descubrir los criterios que han marcado la elección de la agenda informativa, la perspectiva desde la que se han construido ciertos relatos y dibujado a determinados personajes e instituciones, que, si bien puede estar condicionada por una línea editorial, no por ello queda exonerada del deber de proporcionar una formación veraz a la opinión pública. La segunda razón, parafraseando a Melé, es que la consideración ética de la empresa periodística, lejos de poder evaluarse desde el mero cumplimiento de unas normas extrínsecas, "se descubre contemplando la acción en su conjunto y analizando racionalmente cómo afecta al bien de las personas"15.

Ambas cuestiones exigen comprobar si las informaciones han sido contrastadas, si las interpretaciones son plausibles, pero también desterrar el falso sentido de la neutralidad periodística. Como desideratum ético y práctica concreta, la distancia del profesional ante los acontecimientos que narra se sigue sosteniendo, en tantas ocasiones, "en un ritual de defensa que esconde la necesaria construcción de realidad que implica el periodismo y la postura institucional, social y profesional de los periodistas frente a los hechos" ${ }^{16}$. Este oficio obliga a cuestionamientos más profundos y comprometidos. En efecto,

13 Cortina, A.; Conill, J.; Domingo, A. y García Marzá, V. D. (2008); Garriga, E. y Melé, D. (2004); Soria, C. (1991).

14 Richards, I. (2009).

15 Melé, D. (1998), p. 2.

16 San Martín, R. (2008), p. 73. 
como argumenta Restrepo, entre los extremos de la información distorsionada o sesgada y el de la noticia aséptica hay un término medio, tan difícil como la práctica de las virtudes: contar la historia e interpretarla sin restar exactitud, haciéndole sentir al lector que uno está de su lado ${ }^{17}$.

Concretamente, se quiere profundizar en uno de los tópicos de la ética empresarial, el factor confianza, entendido, según esbozan Carmona, Donoso y Reckers, como el "pegamento" que sustenta el comportamiento ético, de tal forma que, una vez se ha malgastado, es muy difícil de recuperar ${ }^{18}$. En este sentido, si la confianza es un componente fundamental en cualquier organización, en la empresa periodística es ineludible.

Son numerosos los supuestos en los que se pueden constatar cómo se desperdicia este "adhesivo" en las noticias publicadas, con el impacto consiguiente en su credibilidad. Además, esto puede suceder tanto si los medios de comunicación reciben ayudas públicas o incluso llegan a ser de titularidad estatal, como si son gestionados por una sociedad mercantil.

\section{LA CONSTRUCCIÓN DEL LÍDER CATÓLICO A TRAVÉS DEL ENFOQUE PERIODÍSTICO}

El caso que se presenta a continuación, enmarcado en una investigación doctoral sobre el tratamiento informativo nacional del pontificado de Benedicto XVI (2005-2013), por razones metodológicas se centra en el diario El País. La razón de haber escogido este rotativo se fundamenta en el hecho de que cuenta con la mayor tirada según la Oficina de Justificación de la Difusión (OJD), por lo que puede haber tenido un ambito considerable de repercusion mediatica ${ }^{19}$. Además, aunque es cierto que la difusión informativa es mayor en el medio televisivo y en internet, la capacidad de influencia de la

17 Restrepo, J. D. (2001), p. 13.

18 Carmona, S.; Donoso, R. y Reckers, P. (2013).

19 Su tiraje en 2019 fue de 158.320 ejemplares y su edición digital roza los veinte millones de usuarios únicos mensuales. El País pertenece al Grupo PRISA (Promotora de Informaciones S. A.), la mayor compañía de comunicación multimedia española. De hecho, cuenta con medios informativos, culturales y educativos en España e Hispanoamérica, con presencia en radio, televisión, prensa escrita y editoriales. Engloba otras marcas informativas como As, Cinco Días o El Huffington Post, Prisa Radio y Prisa TV. Además, el grupo tiene una división editorial, Santillana, presente en España y en 21 países de Iberoamérica desde hace más de 50 años. Por otro lado, Prisa cuenta con parte del accionariado de medios internacionales como Le Monde, el Grupo Media Capital -que es el mayor grupo audiovisual privado de Portugal- y de otros mass media americanos. 
prensa escrita sigue siendo superior ${ }^{20}$. En un momento histórico con un claro predominio de lo audiovisual -donde prevalece lo superfluo y anecdótico- la lectura del periódico impreso sigue resultando crucial:

"A través del impacto emocional de la visión de determinados hechos, se condena indirectamente al desprecio o al silencio a los acontecimientos sin imágenes. Se fomenta así la idea engañosa de que la importancia de los hechos es proporcional a su riqueza en representaciones icónicas, que la palabra es accesoria (...) Ha llegado la hora del texto, de la interpretación y de la reflexión”"21.

Valga esta aclaración sobre la elección del rotativo madrileño para evitar inducir a error respecto a los objetivos que se persiguen. Este artículo no pretende evaluar la actividad de este diario o del grupo empresarial al que pertenece, en el sentido de valorar si su narrativa mediática ha sido guiada por intereses determinados. Lo que procura, en todo caso, es sopesar el tratamiento de la Iglesia católica en la prensa no confesional, considerando que, en general, adolece de un rigor y especialización que de suyo la requiere. Por eso se ha acudido, como ejemplo, a uno de los diarios generalistas de mayor difusión y trayectoria.

Atendiendo a la literatura habida, podemos advertir de que el objeto de este estudio no es original stricto sensu, toda vez que ya se ha abordado previamente el tratamiento informativo de este pontífice en la prensa española, con diversos enfoques ${ }^{22}$. No obstante, no se ha encontrado ningún trabajo que coincida en la muestra (todas las unidades informativas que un rotativo generalista referente ha emitido a lo largo de un pontificado) ni en los fines (atender a los ejes temáticos generales y a las tendencias de estructuración discursiva para valorar la adecuación de su relato sobre la Iglesia católica y discutir, en último término, sobre la ética empresarial y la ética periodística).

20 Pou, M. J. (1998), p. 23.

21 Miralles, R. (2001), pp. 133 y 138.

22 Santos, M.T. y Pérez Dasilva, J. A. (2020); Jiménez Yáñez, R. M. (2017); Pou, M. J. (2006) y (2009); Frisella, L. y González, N. D. (2006); Ordeix, E. y Lazuela, F. (2013); Repiso, R., Rodríguez-Pinto, M. Á. y García García, F. (2013); Sierra, J., Muñoz, P. y Liberal, S. (2013); Cordero, F. (2006); PérezLatre, F. J. (2019). 


\section{HIPÓTESIS. METODOLOGÍA}

En el periodismo, como en la fotografía, el enfoque determina la nitidez o la distorsión del retrato que se tome: si se quiere lograr una imagen nítida, se ha de ajustar el objetivo de modo que el foco coincida con el sensor; si se toma la foto por debajo de dicha distancia, no podrá enfocar y la imagen saldrá borrosa.

Valga este símil para plantear la hipótesis de la que se parte, y que se expresa como sigue: el diario El País ha cubierto el pontificado de Joseph Ratzinger sin abrir apenas el diafragma. La consecuencia ha sido, con carácter inevitable, la distorsión de la imagen ofrecida, tanto del Papa como de la Iglesia católica.

¿Por qué ha ocurrido esto? Se presupone que ha sido determinante el hecho de que se haya empleado un objetivo de focal fija. Sin embargo, hay otros mecanismos ante los que es preciso detenerse. ¿Se han priorizado las informaciones relacionadas con la polémica, el conflicto, el escándalo? El sistema de autoenfoque, ¿ha variado durante los años de mandato en precisión? ¿Han podido condicionar los redactores la luminosidad de las tomas? A la hora de crear opinión ¿se ha dado espacio principalmente a detractores del alemán?

Responder a estas cuestiones ha llevado a desarrollar una investigación que busca desentrañar los mecanismos de la cámara con la que el diario de Prisa ha retratado sus casi ocho años al frente de la Santa Sede. Para ello, se ha diseñado un aparato metodológico basado en el paradigma del framing ${ }^{23}$ con el que se ha podido desarrollar un análisis complejo que considera el impacto de las noticias emitidas entre el 19 de abril de 2005 (día de la elección de Ratzinger) y el 28 de febrero de 2013 (fecha en la que se hizo efectiva su renuncia), en la edición impresa nacional de El País ${ }^{24}$.

En la primera fase del estudio se ha procedido a un doble escrutinio: cronológico, para confirmar cuáles han sido los picos noticiosos en estos ocho años; y cualitativo, descubriendo los asuntos a los que se ha prestado mayor atención. Seguidamente, se ha procedido a un análisis del discurso en los mo-

23 Para aproximarse al paradigma del framing, en las revistas fuente de Comunicación los nombres que más se repiten son los de Juan José Igartua, Carlos Muñiz, María Luisa Humanes, Rosa Berganza, José Javier Sánchez Aranda, María José Canel, Vicente Mariño, López Rabadán y Ardèvol-Abreu.

24 Se han descartado las ediciones regionales y las ampliaciones volcadas en su edición online. La muestra la han conformado 1.407 piezas extraídas de las 2.851 ediciones consultadas. 
mentos más significativos del mandato, una técnica de investigación que persigue "la descripción objetiva, sistemática y cuantitativa del contenido manifiesto en las comunicaciones" 25 . La finalidad ha sido obtener una identificación empírica del relato elaborado sobre este pontificado.

En estas páginas se adelanta una muestra de ese trabajo, centrada en cómo ha sido construida la imagen del líder católico, tomando como referencia temporal el momento de su elección y los días que siguieron a la comunicación pública de su renuncia. Es decir, la investigación presentada en este artículo queda acotada a las noticias publicadas en estos dos momentos por considerar que son ilustrativos para investigar los frames y realizar el análisis del discurso, que se desarrolla a partir del descubrimiento de los encuadres noticiosos latentes, extraídos a partir de expresiones, estereotipos y frases en clave interpretativa ${ }^{26}$.

\section{1. "El gran inquisidor"}

En el balance que el diario El País había realizado sobre los candidatos a sustituir a Juan Pablo II, Ratzinger era un 'gran elector', no un 'papable ${ }^{27}$. Se sabía que había entrado en la asamblea cardenalicia como principal favorito, "pero el rechazo que suscitaba en los sectores reformistas hacía pensar que utilizaría su ascendente para favorecer la elección de otro purpurado con un perfil menos áspero"28. Apremiaba, pues, un cambio en el Gobierno de la Santa Sede (el subtítulo de la primera crónica dedicada a la jornada inicial del cónclave fue una declaración de principios: "los cardenales envían una señal de urgencia al optar por las votaciones desde el primer día" $\left.{ }^{29}\right)$. De hecho, el diario advirtió -con razón de la homilía que el entonces cardenal pronunció en la misa pro eligendo romano pontífice- del líder que le esperaba a la Iglesia si "salía" el bávaro:

25 Berelson, B. (1952), p. 18.

26 Al nombramiento, el rotativo dedicó 31 piezas entre los días 19, 20 y 21 de abril de 2005; la mayoría firmadas por Lola Galán, seguida de Juan Arias y de Enric González. Por su parte, El País dedicó 42 unidades a la renuncia entre el 12 y el 28 de febrero de 2013, rubricadas principalmente por Pablo Ordaz.

27 Pou, M. J. (2006), p. 198.

28 González, E. (2005a), p. 2.

29 Galán, L. (2005a), p. 3. 
"Ratzinger, cuyo anclaje teológico se remonta a Santo Tomás de Aquino y al medievo, hizo un homenaje al inmovilismo [...] Quizá el cardenal alemán quemó sus naves y expresó con claridad ante sus colegas qué tipo de Papa tendrían si le eligieran a él [...] y atacó de forma indirecta las posiciones de quienes propugnaban una adecuación doctrinal a la realidad social contemporánea" ${ }^{30}$.

Sin embargo, el responsable durante cerca de dos décadas de la Congregación para la Doctrina de la Fe fue el elegido y el rotativo lo recibió con sorpresa ("El hombre «tocado» por el Espíritu Santo resultó un Papa a la vez obvio e imposible. Algunas ideas preconcebidas se rompieron. No podía ser Papa un alemán, se decía, por pertenecer a una Iglesia demasiado poderosa y demasiado reformista" ${ }^{31}$ ) y con un enfoque condicionado por la tesis de este periódico: el conflicto que se avecinaba. $Y$ es que el discurso general vino a resaltar que el nombramiento del teólogo iba a agudizar el cisma institucional entre los cardenales 'dogmáticos' y los que desearían un mayor interés hacia los problemas sociales o una reforma de las estructuras eclesiales; también, la inviabilidad de que la Iglesia dé respuesta a los avances sociales, si estos últimos la gobiernan.

Se detallan a continuación los mecanismos empleados para configurar este frame dominante.

El desacuerdo eclesial se ha establecido, fundamentalmente, aludiendo a la labor de Ratzinger al frente del dicasterio de la Fe, equiparado explícitamente con el Tribunal de la Inquisición. Como prefecto, el rotativo sólo ha sacado a colación su rechazo a iniciativas autoproclamadas "progresistas", principalmente su responsabilidad en el silencio impuesto a Leonardo Boff y a otros representantes de la Teología de la Liberación durante la era de Wojtyla.

"Se aleja de la línea progresista defendida en el Vaticano II para iniciar un camino cada vez más conservador. Hasta el punto de sintonizar completamente con Juan Pablo II, el papa polaco que trae a Roma un catolicismo arcaico [...] Ratzinger se convierte en el gran represor de los teólogos disidentes, de todo estudioso que ose alejarse de la línea maestra dictada en el Vaticano" 32 .

30 González, E. (2005b), p. 4.

31 González, E.(2005a).p. 2.

32 Galán, L. (2005b), p. 3. 
Esta lectura unívoca sobre el trabajo desempeñado al frente del dicasterio de la Fe ha sido el principal argumento para elaborar su perfil. Ahora bien, si alguna crónica ha admitido la altura intelectual de Ratzinger ("Es un teólogo brillante, muy reconocido en todo el mundo" ${ }^{33}$, "un intelectual de prestigio que habla seis lenguas y tiene más de 30 libros publicados"34), la casi totalidad de las crónicas ha acentuado su carácter "emocionalmente frío, dogmático e incluso fundamentalista"35: 'Gran Inquisidor', 'hombre de hierro'36, 'guardián inflexible de la doctrina y azote de teólogos innovadores ${ }^{377}$ son algunos de los sobrenombres referidos.

El resultado ha sido presentar al nuevo pontífice como exponente de una confrontación entre la tradición y modernización que siempre ha generado controversia en la Iglesia. Por ello, su elección ha causado desconcierto en no pocos sectores que, "al contrario que Benedicto XVI, no lo tienen todo tan claro" ${ }^{38}$. De hecho, el diario se ha preguntado cómo se tradujo esta división, sobre todo en su país natal, apuntando incluso que "la mayoría de los siete cardenales alemanes no eligió a Ratzinger" ${ }^{39}$ :

"La elección del cardenal Joseph Ratzinger como nuevo Papa divide a los católicos y a la opinión pública en su Alemania natal. Se puede hablar de sensación agridulce. A la satisfacción y el orgullo de que un compatriota haya llegado a líder de los mil millones de católicos de todo el mundo se unen y mezclan la preocupación por el inmovilismo y la cerrazón que Benedicto XVI puede imponer a su pontificado" ${ }^{40}$.

"Fueron muchos quienes recordaron la dura homilía del lunes y dieron por supuesto un papado seco, hosco [...] No debería esperarse de Benedicto XVI un Concilio Vaticano III. Más bien al contrario. Algunas de las reformas del Vaticano II le parecen erróneas, y quizá intente restaurar parcialmente el viejo rito latino y el canto gregoriano"41.

En este relato también se han lanzado previsiones sobre su nueva etapa en la sede de Pedro, en la que se acentuará el encaramiento de Roma con la

\footnotetext{
33 Ellegiers, S. (2005), p. 6.

34 Galán, L. (2005c), p. 4.

35 Ellegiers, S. (2005), p. 6.

36 Galán, L. (2005b), p. 3.

37 González, E. (2005a), p. 2.

38 Galán, L. (2005b), p. 3.

39 Ellegiers, S. (2005), p. 6.

40 Comas, J. (2005), p. 5.

41 González, E. (2005b), p. 5.
} 
sociedad, particularmente en Alemania (donde "amplios sectores de la población ven con mirada crítica el férreo conservadurismo de Ratzinger" ${ }^{42}$ ) y en España (que "oscila entre la «grandísima alegría» del Opus y la decepción de católicos de base" $\left.{ }^{\prime 3}\right)$.

Por otro lado, los textos han incluido terminología propia de la información política, cuya naturaleza, per se, remite a la pugna, a la colisión:

"No ha salido un papa de centro, como casi todos los analistas esperaban, un papa de compromiso entre la línea dura e inflexible del cardenal Ratzinger y los que abogaban, sobre todo en el Tercer Mundo [...] La pregunta que ayer se hacían aquí en Brasil los analistas religiosos es cómo fue posible que los cardenales del Tercer Mundo, empeñados en la lucha contra la miseria, los de la teología de la liberación, dieran su voto al cardenal más rígido del cónclave en materia de fe y de moral" ${ }^{\prime 4}$.

\subsection{El Papa "tira la toalla"}

Con un comunicado leído en latín, Ratzinger anunció el 11 de febrero de 2013 que dejaba el trono de Pedro en sede vacante. Los cardenales se dispusieron entonces para participar en un cónclave, tan histórico como inusual, que se encargaría de elegir al sucesor de Benedicto XVI estando aún en vida. Millones de personas atendían a los detalles que ofrecían los medios de comunicación, que esos días siguieron publicando corruptelas de la curia.

La extraordinaria renuncia copó, pues, los diarios internacionales, que no sólo anunciaron esta decisión, sino que trataron de interpretar el paso dado por Ratzinger, las razones y el alcance del mismo, en noticias donde los datos se entremezclaron con especulaciones, impresiones y elucubraciones personales. Incluso el diario de la Santa Sede se aventuró a publicar en primera página que el Papa había actuado con "desconcertante dignidad" 45 .

¿Cuál fue el frame de El País? El conflicto, porque prácticamente todas las informaciones retransmitieron la dimisión en el marco de luchas intestinas de poder. El objetivo de la cámara, no obstante, plasmó este enfoque desde distintos ángulos. Con la mirada puesta en la fragilidad física y psicológica de

\footnotetext{
42 Fleta, C. (2005), p. 6.

43 Bedoya, J. G. (2005), p. 9.

44 Arias, J. (2005), p. 10.

45 Ordaz, P. (2013c), p. 2.
} 
Ratzinger, planteó al lector si había sido un gesto libre, humilde, o más bien lo contrario, una derrota. La crisis que se abría en Roma (al relegar su ministerio, pero sin dejar de ser pontífice) fue también un punto de vista en el relato, que sacó a colación continuamente los problemas que arrastraba la Iglesia. Asimismo, la interpretación de que esta decisión revolucionaba la percepción de la jerarquía eclesiástica fue una constante: el profesor de teología alemán renegaba del poder temporal y espiritual que le había sido dado por gracia divina.

Por otro lado, la sorpresa de que el Papa se retirara voluntariamente del puesto de sucesor de Pedro -algo que nunca había sucedido en la era modernaera mayúscula al venir de un perfil que el periódico había bosquejado como eminentemente reaccionario.

Así, va a tratar de explicitarse estos enfoques en algunos de los textos que, en apenas dos semanas, inundaron las páginas de la cabecera madrileña.

Desde que el Papa anunciara al mundo su renuncia, sus mensajes, de obra y de palabra, fueron analizados exhaustivamente. Unos periodistas los acogieron como llenos de fuerza y claridad, explicando al lector que el alemán parecía haber alcanzado la determinación que, según sus críticos, le faltó durante su pontificado. Otros, sin embargo, los tradujeron como señal inequívoca de su debilidad personal. El conflicto, sin embargo, fue latente en ambas posiciones. En la primera, el representante de Dios en la tierra batallaba con coraje su último combate contra los 'lobos' y los 'cuervos'. En la segunda, un hombre anciano y enfermo renunciaba vencido, no tanto por la edad y la salud como por su cargo.

"Dentro de unos días, las librerías se llenarán de obras urgentes sobre Benedicto XVI, el papa que renunció. Habrá unas que glosen su figura tranquila, la del teólogo que jamás levantó la voz, y otras que busquen el éxito mezclando el aroma del incienso con el de la conspiración [...] Estos 17 días que Joseph Ratzinger se ha reservado para enderezar algunos de los renglones torcidos. Libre de todos y de sí mismo, su voz ha clamado contra la corrupción en la Iglesia y su mano no ha temblado al enviar lejos del Vaticano a quienes ya no considera dignos de su confianza" ${ }^{46}$.

"El papado de Benedicto XVI ha estado caracterizado por las luchas internas del Vaticano para contrarrestar sus intentos -no por tardíos menos ta-

46 Ordaz, P. (2013b), p. 2. 
jantes- de limpiar la Iglesia de clérigos pederastas y banqueros corruptos. La filtración masiva de sus documentos privados es un ejemplo. Y otro, muy revelador, la manera de despedirse. Ratzinger, de 85 años, se marcha como vivió, solo" ${ }^{\prime 4}$.

"Va quedando meridianamente clara la razón del adiós. Después de casi ocho años intentando sin éxito poner cordura en la casa de Dios, Ratzinger decidió pasar el testigo, preocupado sin duda porque su progresivo deterioro pueda ser aprovechado por las distintas facciones que luchan por el poder en el seno de la Iglesia" 48 .

Un punto fundamental en el relato fue el cónclave que tuvo lugar en marzo y que había cogido por sorpresa a la opinión pública, pero sobre todo a los cardenales que fueron convocados. Se celebraría no sólo con su antecesor vivo -algo inédito en la historia-, sino en un momento en el que el Vaticano (incluyendo a los hombres más cercanos al Santo Padre) se veía envuelto en el thriller de las filtraciones de los documentos secretos.

No hace falta insistir en las divisiones internas y la lacra de contrariedades acumuladas y acuciantes que El País había hecho públicos durante los casi ocho años de mandato de Ratzinger. El frame, en este sentido, es que los disgustos que habían ensombrecido su papado oscurecerían, así mismo, a su sucesor:

"Por empezar por el asunto más grave, el de la pederastia, Benedicto XVI llegó con la orden de apartar de sus cargos a los encubridores, pero han pasado los años sin haberlo logrado [...]. Ocho años más tarde, el clamor por la suciedad continúa [...]. Se une ahora el escándalo del espionaje (Vatileaks); los enfrentamientos entre cardenales con poder y la resistencia a hacer cumplir sus órdenes" $"$.

"Es una cuestión -la del papel que jugará Ratzinger tras su renuncia- que preocupa en el Vaticano, sobre todo después del contenido que el todavía Papa ha querido imprimir a sus últimos discursos y a sus últimas decisiones, especialmente en relación con el escándalo Vatileaks y con las finanzas vaticanas" ${ }^{50}$.

47 Ordaz, P. (2013c), p. 2

48 Ordaz, P. (2013d), p. 3.

49 Bedoya, J. G. (2013a), pp. 8-9.

50 Ordaz, P. (2013e), p. 5. 
"Los dos grandes escándalos que la Iglesia sigue intentando cerrar en falso, la protección durante décadas a los curas pederastas y la corrupción moral y económica de algunos miembros de la curia romana, se acaban de presentar en el zaguán del Vaticano justo en el momento más delicado, la renuncia de Benedicto XVI y la elección del nuevo papa" ${ }^{51}$.

Por otro lado, su decisión podía conducir al desmantelamiento de un organigrama de poder cada vez más alejado de las necesidades de los fieles. Así, hubo relatos que 'mundanizaron' el cuerpo católico, no sin ironía; otros acudieron a historiadores y teólogos que coincidieron en señalar que la renuncia de Benedicto XVI desacralizaba la figura del pontífice ${ }^{52}$. En ambos casos, no obstante, se reforzó la perspectiva del periódico: Ratzinger rebajó una figura, un cargo para elegidos que solo se abandonaba para pasar al Reino de los Cielos. Su decisión había abierto un nuevo camino, más terrenal, en la dinastía pontificia; una grieta en la roca sobre la que está edificada la Iglesia o, quién sabe, su final:

“Así las cosas, cabría pensar que, si el Espíritu Santo otorgó a Ratzinger la gracia de estado para acceder al pontificado y ejercer este magisterio, igualmente ha podido retirarle esta gracia por razones inescrutables e inefables propias del Paráclito" ${ }^{53}$.

"Ese es también el Vaticano que abandona Ratzinger. Una estructura de poder tan anticuada, tan protegida de los cientos de millones de verdaderos católicos por altísimos muros de soberbia, que se ha mostrado incapaz durante décadas de escuchar, por ejemplo, el clamor contra la pederastia, el llanto de las víctimas, la protección infame de los culpables" ${ }^{54}$.

"Hasta ahora, los papas no se despedían. Dios los recogía en su seno y, pasados unos días, el Espíritu Santo sobrevolaba la Capilla Sixtina para que los cardenales reunidos en cónclave acertaran al elegir al nuevo sucesor de Pedro. La renuncia de Benedicto XVI abre un tiempo nuevo, de dudas y también de peligros" $" 55$.

51 Ordaz, P. (2013f), p. 2.

52 Tobella, A. y González Vejo, S. (2013), p. 8.

53 Bedoya, J. G. (2013c), p. 2.

54 Bedoya, J. G. (2013b), p. 2.

55 Ordaz, P. (2013h), p. 4. 
Concluyendo, las "fotografías" presentaron, en esta ocasión, matices. Se pueden colegir algunos argumentos que valoraron la decisión del alemán ${ }^{56}$. Por otro lado, el relato mediático culpabilizó a Ratzinger (aduciendo su falta de carácter y su equivocada manera de elegir a los colaboradores, atribuyéndole la responsabilidad de la situación en que quedaba la Iglesia, presentando su decisión como un visaje de ruptura, como una deserción...) También hubo alguna pieza que, desde un terreno neutral, se lanzó a la búsqueda de precedentes que amortiguaran el alcance del acontecimiento:

"Ratzinger se va porque no puede con la Iglesia, porque nunca pudo [...] jamás gozó del apoyo de la Curia [...] Por esto, a medida que pasan las horas, algunos analistas se van apartando de la tesis de que Ratzinger ha sido víctima de las intrigas para sostener casi la contraria: su incapacidad para gobernar la Iglesia ha provocado el desgobierno" ${ }^{57}$.

"En la mañana de ayer, los quioscos de Roma dejaban claro que, además de la sorpresa, la prensa italiana e internacional resaltaba la coherencia de la decisión de Benedicto XVI. Su sinceridad al reconocer su cansancio, pedir perdón y marcharse" $"$.

"La decisión de Benedicto XVI no carece de base jurídica. El Código de Derecho Canónico (una especie de Constitución interna de la Iglesia), promulgado por su antecesor, Juan Pablo II, en 1983, contempla la posibilidad de que un Papa dimita [...] Dicho en otras palabras, el Papa puede tomar la decisión soberana de abandonar" ${ }^{59}$.

\section{CONCLUSIONES}

1. El análisis del discurso en la muestra seleccionada evidencia que Benedicto XVI ha sido presentado como un personaje conflictivo. En el cónclave se ha advertido del nombramiento de un cardenal fundamentalista que ha decepcionado a los que desearían un mayor interés de la Iglesia hacia los problemas sociales o una reforma de las estructuras eclesiales. Por su parte, en su

56 Sahuquillo, M. R. (2013), p. 13.

57 Ordaz, P. (2013g), p. 4.

58 Ordaz, P. (2013c), p. 2.

59 Galán, L. (2013), p. 13. 
renuncia ha prevalecido el cliché de su fragilidad ante el cargo y de su falta de liderazgo.

2. Respecto a la hipótesis general, debe esperarse a concluir la investigación para dilucidar la apertura del diafragma de El País a la hora de fotografiar este papado. No obstante, cabe afirmar que, en la muestra analizada, el diario ha cerrado el foco: el retrato ofrecido de Ratzinger en su nombramiento se ha tomado exclusivamente en el escenario de la Congregación para la Doctrina de la Fe, obviando su trayectoria vital o académica; además, su rol al frente del dicasterio romano se ha identificado con su personalidad y con lo que, se prevé, será su labor al frente de la Iglesia romana. Por su parte, la renuncia ha sido contextualizada en medio de las corruptelas vaticanas, recordadas en cada información y apuntadas como causa determinante de la decisión.

\section{DISCUSIÓN}

Estos hallazgos se ofrecen a expertos en ética empresarial para que puedan debatir sobre la condición de la prensa como servicio público. Entre tantos asuntos que podrían ponerse en diálogo, se sugieren tres: la necesidad de la especialización del producto para recuperar la confianza del ciudadano; la inadecuación del lenguaje de la pura mercadotecnia en este sector; y el compromiso de las organizaciones por ser lugares que promuevan virtudes profesionales y contribuyan al logro del denominado meaningful work ${ }^{60}$. Se trataría, en definitiva, de organizaciones que hagan suyo en su credo corporativo el concepto aristotélico de eudaimonia, que se puede traducir -en la línea de Melé- como 'prosperidad humana' o 'desarrollo humano' ${ }^{61}$.

\subsection{Especialización profesional, relaciones institucionales óptimas}

De los resultados expuestos puede extraerse una idea general, según la cual, El País ha incurrido en algunos de los riesgos sobre los que la literatura advierte en la prensa generalista nacional a la hora de informar sobre el hecho religioso. Los más evidentes se concretan en haber aplicado criterios propios de la información política y en que entre los valores noticia haya prevalecido el conflicto ${ }^{62}$.

60 Beadle, R. y Knight, K. (2012).

61 Melé, D. (2014).

62 Pou, M. J. (2008) y (2009). 
Este diario, no obstante, es solo un ejemplo de las deficiencias comunes a la práctica periodística general, de modo que se puede concluir afirmando, con Contreras, que "los males de la información religiosa -cuando existen- son los males del periodismo. Y su solución hay que buscarla en la calidad profesional" ${ }^{63}$.

Entre otras razones que obstaculizan la producción de la información religiosa, los expertos se refieren fundamentalmente a dos: que esta temática no se incluya entre las areas de especializacion periodística y el especial "clima de sospecha" habido entre la institución católica y las empresas de comunicación ${ }^{64}$.

Todo lo que envuelve a la Iglesia católica se convierte en una temática con una complejidad particular, principalmente por tratarse de una organización cuya naturaleza le hace difícilmente asimilable a otras. Así, los requisitos específicos que esta dificultad comporta para el informador deben remitir al reto profesional de la especialización, más aún cuando los expertos advierten de que la información religiosa sigue siendo una de las áreas que cuenta con menor presencia en la investigacion, la producción científica y la ensenanza del periodismo en Espana.

Por otro lado, lo constatado en el análisis de prensa lleva a preguntarse por las relaciones entre los agentes que intervienen en este tipo de información, puesto que está generalizada en la Iglesia la queja sobre la insuficiente formación de los periodistas y, a su vez, la crítica de los redactores hacia el hermetismo y poca destreza comunicativa de la jerarquía ${ }^{65}$.

En otros países europeos, la importancia que está adquiriendo la información religiosa puede reconocerse en el esfuerzo de los diarios de prestigio por contar con periodistas especializados en este campo; también, en el de la propia institución, que, de un tiempo a esta parte, ha mostrado un interés paralelo por dotarse de instrumentos específicos para hacer sentir su voz de un modo cada vez más adecuado ${ }^{66}$. Así pues, en España apremia seguir proponiendo soluciones en este doble sentido, en aras de un tratamiento adecuado sobre dicha realidad informativa.

63 Contreras, D. (2005), p. 167,

64 Serrano, J.F. (2004), pp. 404-405.

65 Díez Bosch, M. (2006), p. 70.

66 Contreras, D. (2004), p. 13. 


\subsection{LA ÉTICA INFORMATIVA FRENTE A LAS 'FUERZAS' SOCIOECONÓMICAS}

Una segunda cuestión que puede discutirse a la luz del caso observado es en qué medida los periodistas se ven abocados a perfilar retratos de personajes o instituciones siguiendo el "dictado" de una línea empresarial, y hasta qué punto está en juego la legitimidad de un medio de comunicación cuando se dedica a lanzar informaciones sobre personajes públicos sin estar debidamente contrastadas. Como señala Richards:

"Aunque el periodista individual es una unidad esencial de la agencia ética, los periodistas son, cada vez más, empleados de grandes empresas o corporaciones cuyo objetivo principal es maximizar los beneficios para los accionistas. Por consiguiente, muchos, tal vez la mayoría, de los dilemas éticos a los que se enfrentan los periodistas comienzan con el conflicto inherente entre el papel del individuo como periodista y la búsqueda de beneficios por parte de su empleador" ${ }^{67}$.

Esta situación no es única, otros campos se enfrentan a controversias similares. Por consiguiente, el examen de las ideas ofrecidas por quienes operan desde la perspectiva de la ética empresarial puede facilitar el análisis de la interfaz entre los periodistas individuales y las fuerzas empresariales que afectan a tantos de ellos.

Un primer punto en el que cabe detenerse se concreta en el reduccionismo de entender únicamente la prensa como negocio. Esto ha supuesto para muchos medios de comunicación "implantar el lenguaje de la mercadotecnia de consumo en la información. Los lectores y los espectadores se han convertido en clientes, entenderlos forma parte del marketing" ${ }^{18}$. Como argumenta Chillón, las empresas periodísticas sirven a la sociedad ofreciéndoles bienes al modo en que lo hacen las instituciones educativas o los centros sanitarios. Sin embargo, si la ciudadanía no cuestiona el hecho de que ciertas compañías gestionen esos bienes, ¿por qué se alzan tales sospechas en el caso del bien de la información? En su opinión, la respuesta tiene que ver con un movimiento de las sociedades periodísticas exactamente contrario y opuesto a las demás: si el posicionamiento de ciertas empresas educativas o sanitarias ha implicado la inversión creciente en profesionales preparados, no así en el periodismo in-

67 Richards, I. (2009), p. 119.

68 Kovach, B. y Rosenstiel, T. (2003), p. 85. 
formativo ${ }^{69}$. En este sentido, conviene seguir innovando en las industrias de prensa para jugar la partida al revés ${ }^{70}$.

Ello enlazaría también con el diálogo ético de las empresas de comunicación con sus stakeholders. Y es que, según expone Aznar, en la actualidad se genera una relación vertical y asimétrica entre emisores y receptores, en la que el público desconoce al emisor (su identidad, técnicas, criterios, valores) y éste ignora a aquél (sus necesidades, demandas, derechos) ${ }^{71}$. Sin embargo, esta tendencia puede cambiarse, sosteniendo que las empresas informativas "poseen capacidades específicas, y potencialmente muy importantes, cuando se trata de crear, o ayudar a construir, arenas públicas de ciudadanía"72. De hecho, hay estudios que están sacando a colación propuestas variadas ${ }^{73}$.

Por otra parte, la ética en los medios de comunicación está llamada a lidiar con otro problema: el hecho de que la información sea un poder muy codiciado por el mundo político y económico. Sin embargo, frente a quienes sostienen que ninguna empresa dedicada a la comunicación puede subsistir sin la financiación de determinados organismos públicos y privados, y que, por lo tanto, su independencia es ilusoria, cabe reivindicar su imparcialidad y su altura de miras. En este sentido, también se han iniciado investigaciones ${ }^{74}$.

En cualquier caso, la razón de ser de un medio de comunicación como servicio público es insoslayable. La sociedad tiene derecho a la información y los poderes públicos están llamados a garantizar la operatividad de los mass media, públicos y privados, en condiciones de equidad. Por ello, el planteamiento de estas cuestiones debe alejarse de la identificación de lo público con lo gubernamental, como polo opuesto a lo privado/comercial. Por un lado, porque el asunto no es tan simple y, por otro, porque no ha de confundirse la reivindicación del servicio público de comunicación con el estatalismo monopolista. De este modo, se cuenta con estudios que tratan de identificar los antagonismos de la esfera contemporánea de los medios sociales en los ámbitos de la economía, el Estado y la sociedad civil ${ }^{75}$.

69 Chillón, J. M. (2011).

70 Painter-Morland, M. y Deslandes, G. (2017); Sjøvaag, H. y Krumsvik, A. H. (2018).

71 Aznar, H. (2005), p. 214.

72 Moon, J.; Whelan, G. y Grant B. (2013), p. 777.

73 Stern, R. J. (2008), Wahl-Jorgensen, K. (2007).

74 Kanagaretnam, K.; Lee, J.; Lim, C. Y. y Lobo, G. J. (2018); Phillips, A. (2010); Allen, D. S. (2008).

75 Fuchs, C. (2014); Horowitz, M. A. y Nieminen, H. (2017). 


\subsection{Asumiendo la 'eudaimonia'}

La independencia de la información no es sólo una garantía para los derechos de los lectores, sino que su salvaguarda constituye la razón última del trabajo profesional, que es el tercer ítem al que ha querido atenderse. Es el rasgo que debe definir a las empresas en este sector; en el que, a su vez, debe regir un marco jurídico y social que anime a los periodistas a respetar y seguir los valores de su oficio.

Defenderla implica tomar posición desde distintos frentes, que, insisto, deben definir expertos en ética de las organizaciones. El primero de ellos supondría postular la necesidad de que todos los agentes que intervienen en la comunicación asuman su cuota de responsabilidad y elaborar programas para ello. Los enunciados deontológicos en las empresas informativas, "aun aceptados en abstracto, no siempre son debidamente aplicados a la práctica" 76 . Como en otros sectores, no son suficientes para la incorporación de la ética en la empresa; incluso hay quien señala que son respuestas superficiales ${ }^{77}$. Esta perspectiva está reforzada por estudios empíricos que muestran que los empleados que tienen programas basados en acciones éticas, evitan los comportamientos deshonestos, buscan consejo cuando se ven enfrentados a dilemas morales y están más comprometidos con la organización ${ }^{78}$.

Otra propuesta sería que instituciones educativas y empresariales, académicos y profesionales, tomen en consideración el propósito de la enseñanza y la formación en ética empresarial, y que reivindiquen la correcta satisfacción de una información veraz como un derecho y como un bien ${ }^{79}$.

Finalmente, cabe la asunción generalizada del fin último de este oficio, que no es el beneficio económico, ni tan siquiera informar, sino, en todo caso, promover la búsqueda del bien común. En efecto, no se puede recurrir indiscriminadamente al derecho a la información, como pauta de actuación que relegue otros derechos de carácter sustantivo que pueden invocar para sí los destinatarios de la noticia. Se impone la superación de la dicotomía ya clásica sugerida por Max Weber entre la ética de la convicción y la ética de la res-

76 Melé, D. (1998), p. 13.

77 Huang, Y. H. (2001); Warren, R. C. (1993); Webley, S. y Werner, A. (2008).

78 Weber, J. y Wasieleski, D. (2013); Trevino, L. K.; Weaver, G. R.; Gibson, D. G. Y Toffler, B. L. (1999).

79 Harris, H. (2008). 
ponsabilidad $^{80}$. Tanto es así, que se están publicando trabajos que proponen pautas para juzgar determinados "paisajes" de los mass media en la medida en que apoyan y permiten una comunicación ideal, entendida como la satisfacción de normas de inclusión, apertura y justicia ${ }^{81}$.

En definitiva, para que los medios de comunicación puedan prestar este servicio, citando a Benedicto XVI, "es preciso comprender cada vez mejor las perspectivas y la responsabilidad que implica su desarrollo con vistas a las consecuencias concretas que tiene para la conciencia y la mentalidad de las personas, así como para la formación de la opinión pública"82.

Estas páginas han acogido esta última apelación con tal de subrayar, aunque sea desde la sencillez del caso presentado, el cometido trascendente que tienen ante sí quienes trabajan en este sector, reconociendo que precisamente por el hecho de ser un servicio público se exige también una búsqueda sincera de la verdad, así como la defensa de la dignidad de la persona humana en todas sus dimensiones. Quizás así sea posible un periodismo que aúne la rentabilidad y la excelencia.

80 Weber, M. (1993).

81 Fuchs, C. (2020), Krüger, F. (2016).

82 Benedicto XVI (2005). 


\section{BIBLIOGRAFÍA}

Allen, David S. (2008), "The Trouble with Transparency", fournalism Studies, vol. 9, $\mathrm{n}^{\circ}$ 3, pp. 323-340.

Ardèvol, Alberto (2015), "Framing o teoría del encuadre en comunicación. Orígenes, desarrollo y panorama actual en España”, Revista Latina de Comunicación Social, vol. 70, pp. 423-450.

Arias, Juan (2005), "Un teólogo sólido e inflexible”, El País, 20 de abril, p. 10.

Aznar, Hugo (2005), Ética de la comunicación y nuevos retos sociales: códigos y recomendaciones para los medios, Paidós, Barcelona.

Bañón, Alexis; Guillén, Manuel y Ramos, Nataly (2011), "La Empresa Ética y Responsable”, Universia Business Review, vol. 30, n 2, pp. 32-43.

Baruh, Lemi y Popescu, Mihaela (2017), "Big Data Analytics and the Limits of Privacy Self-Management", New Media \& Society, vol. 19, n 4, pp. 579596.

Beadle, Ron y Knight, Kelvin (2012), "Virtue and Meaningful Work", Business Ethics Quarterly, vol. 22, n 2, pp. 433-450.

Bedoya, Juan G. (2005), "España oscila entre la «grandísima alegría» del Opus y la decepción de católicos de base", El País, 21 de abril, p. 9.

Bedoya, Juan G. (2013a), "El Papa que quería limpiar la Iglesia tira la toalla”, El País, 12 de febrero, pp. 8-9.

Bedoya, Juan G. (2013b), “El Papa renuncia para limpiar el Vaticano”, El País, 13 de febrero.

Bedoya, Juan G. (2013c), "Falible. Expapa. Un poderoso en retiro", $E l$ País, 24 de febrero.

Benedicto XVI (2005), Audiencia de Su Santidad Benedicto XVI a los representantes de los medios de comunicación social, 23 de abril.

Berelson, Bernard (1952), Content Analysis in Communication Researches, Free Press, Michigan.

Blázquez, Niceto (2002), La nueva ética en los medios de comunicación. Problemas y dilemas de los informadores, BAC, Madrid. 
Carmona, Salvador; Donoso, Rafael y Reckers, Philip (2013), "Timing in Accountability and Trust Relationships", Journal Business Ethics, vol. 112, n 3 , pp. 481-495.

Chillón, José Manuel (2011), "Ética y empresa informativa: notas para un discurso integrador", Comunicación y hombre, vol. 7, pp. 107-118.

Comas, José (2005), "No todos los alemanes lo celebran”, El País, 21 de abril, p. 5 .

Contreras, Diego (2004), La Iglesia católica en la prensa, Eunsa, Pamplona.

Contreras, Diego (2005), "La Iglesia de papel. La prensa y las intervenciones de la jerarquía eclesiástica” en Izquierdo, César y Soler, Carlos (eds.), Cristianos y democracia, Eunsa, Pamplona, pp. 145-167.

Cordero, Fernando (2006), "El tratamiento del Papa Benedicto XVI en los géneros informativos de la prensa española", Estudios sobre el Mensaje Periodístico, 12, pp. 103-114.

Cortina, Adela; Conill, Jesús; Domingo, Agustín y García, Vicente Domingo (2005), Ética de la empresa. Claves para una nueva cultura empresarial, Trotta, Madrid.

Craft, Stephanie; Vos, Tim P. y Wolfgang, J. David (2015), "Reader Comments as Press Criticism: Implications for the Journalistic Field", Fournalism, vol. 17, $\mathrm{n}^{\circ} 6$, pp. 677-693.

Díez Bosch, Miriam (2006), "La información religiosa. Hacia una naturalización del periodismo religioso en los medios" en Srampickal, Jacob; Baugh, Lloyd y Mazza, Giuseppe. (eds.), CrossConnections. Interdisciplinary Communications Studies at the Gregorian University, Gregorian \& Biblical Press, Roma, pp. 67-76.

Djerf-Pierre, Monika; Ekström, Mats y Johansson, Bengt (2013), "Policy Failure or Moral Scandal? Political Accountability, Journalism and the New Public Management", Media, Culture and Society, vol. 35, nº 8, pp. 960 976.

Eberholst, Mads Kæmsgaard; Hartley, Jannie M. y Olsen, Maria Bendix (2016), "Between Ideals and Practice: Journalism Students Facing Ethical Dilemmas in Online Newsroom Teaching-Lessons from Denmark", Fournalism and Mass Communication Educator, vol. 2, n 7, pp. 189-202. 
Ellegiers, Sandra (2005), "Alemania recibe con alegría la elección de un bávaro como nuevo pontífice”, El País, 20 de abril, p. 6.

Escobar, Guillermo (2002), Estatuto de los periodistas. Régimen normativo de la profesión y organización de las empresas de comunicación, Tecnos, Madrid.

Ettema, James S. y Glasser, Theodore L. (1987), "Public Accountability or Public Relations? Newspaper Ombudsmen Define their Role", fournalism Quarterly, vol. 64, n 1, pp. 3-11.

Figueras, Mónica, Mauri, Marcel; Alsius, Salvador y Salgado, Francesc (2012), "La precariedad te hace dócil. Problemas que afectan a la profesión periodística”, El Profesional de la Información, vol. 21, nº 1, pp. 70-75.

Fleta, Cecilia (2005), “«Hacía mucho que la catedral no se llenaba»”, El País, 21 de abril, p. 6.

Frisella, Lorena y González, Néstor Daniel (2006), "Habemus Papa. Acerca de la construcción informativa de los diarios españoles en la elección del nuevo pontífice" Question, vol. 9, $\mathrm{n}^{\mathrm{o}}$ 1, pp. 1-11.

Fuchs, Christian (2014), "Social Media and the Public Sphere", TripleC: Communication, Capitalism \& Critique, vol. 12, no 1, pp. 57-101.

Fuchs, Christian (2020), "The Ethics of the Digital Commons”, fournal of Media Ethics, vol. 35, n 2, pp. 112-126.

Galán, Lola (2005a), "El cónclave comienza con fumata negra”, El País, 19 de abril, p. 3 .

Galán, Lola (2005b), "Un cardenal de hierro al frente de la Iglesia”, El País, 20 de abril, p. 3.

Galán, Lola (2005c), "La agenda inmediata del pontífice incluye un viaje a Alemania y cambios en la curia", El País, 21 de abril, p. 4.

Galán, Lola (2013), "Un adiós con remotos precedentes”, El País, 12 de febrero, p. 12.

García de Torres, Elvira y Farmer, Yanick (2017). "Ética en los medios de comunicación: retos y oportunidades para la investigación”, El Profesional de la Información, vol. 26, $\mathrm{n}^{\circ}$ 2, pp. 153-157.

Garriga, Elisabet y Melé, Domènec (2004), "Corporate Social Responsibility Theories: Mapping the Territory", Fournal of Business Ethics, vol. 53, $\mathrm{n}^{\circ}$ 1-2, pp. 51-71. 
Gil de Zúñiga, Homero y Hinsley, Amber (2013), "The Press Versus the Public. What is 'Good Journalism'?”, Journalism Studies, vol. 14, n 6, pp. 926942.

González, Enric (2005a), "Ratzinger se convierte en Benedicto XVI", El País, 20 de abril, p. 2.

González, Enric (2005b), "Ratzinger defiende la ortodoxia frente a los vientos de cambio", El País, 19 de abril, p. 4.

Harris, Howard (2008), "Promoting Ethical Reflection in the Teaching of Business Ethics", Business Ethics: A European Review, vol. 17, n 4, pp. 379390.

Horowitz, Minna Aslama y Nieminen, Hannu (2017), "Diversity and Rights. Connecting Media Reform and Public Service Media", IC Revista Científica de Información y Comunicación, vol. 14, pp. 99-119.

Huang, Yi-Hui (2001), "Should a Public Relations Code of Ethics be Enforced?", Fournal of Business Ethics, vol. 31, n 3, pp. 259-270.

Humanes, María Luisa e Igartua, Juan José (2004), Teoría e investigación en comunicación social, Síntesis, Madrid.

Jiménez Yáñez, Ricardo María (2017), "La representación de la religión en editoriales de cuatro periódicos españoles (2009-2010)". Universidad de Navarra, tesis doctoral.

Kanagaretnam, Kiridaran; Lee, Jimmy; Lim, Chee Yeow y Lobo, Gerald J. (2018), "Cross-Country Evidence on the Role of Independent Media in Constraining Corporate Tax Aggressiveness", Fournal of Business Ethics, vol. 150, n 3, pp. 879-902. Madrid.

Kovac, Bill y Rosenstiel, Tom (2012), Los elementos del periodismo. Aguilar,

Krüger, Franz (2016), "Discourse Ethics and the Media", African Fournalism Studies, vol. 37, ${ }^{\circ}$ 1, pp. 21-39.

Lambeth, Edmund B. (1992), Committed fournalism: An Ethic for the profession, Indiana University Press, Bloomington.

Lee, Angela M. y Chyi, Hsiang I. (2014), "When Newsworthy is not Noteworthy: Examining the Value of News from the Audience's Perspective", Fournalism Studies, vol. 15, nº 6, pp. 807-820. 
Maciá-Barber, Carlos (2014), "La sostenibilidad ética de la empresa periodística: la percepción y el discurso de los directivos de los medios", Dilemata, vol. 14, pp. 19-35.

Marirrodriga, Jorge (2005), "Éxodo hacia el protestantismo", El País, 19 de abril, p. 6.

Martínez Albertos, José Luis (1974), Curso general de redacción periodística, ATE, Barcelona.

McQuail, Denis (1992), La acción de los medios, los medios de comunicación y el interés público, Amorrortu, Buenos Aires.

Melé, Domènec (1998), "Ética de la comunicación publicitaria: Criterios de la enseñanza social católica”, Documento de investigación, vol. 366, pp. 1-14.

Melé, Domènec (2020), Business Ethics in Action: Managing Human Excellence in Organizations, Red Globe Press, Londres.

Merrill, John C. (1997), Journalism Ethics: Philosophical Foundations for News Media, St. Martin's Press, Nueva York.

Meyers, Christopher (2010), fournalism Ethics: A Philosophical Approach, Oxford University Press, Nueva York.

Miralles, Rafael (2001), "La prensa escrita ante el desafío de los nuevos medios", Comunicar, n 16, pp. 131-139.

Moon, Jeremy; Whelan, Glen y Grant, Bettina (2013), "Corporations and Citizenship Arenas in the Age of Social Media", Fournal of Business Ethics, vol. $118, \mathrm{n}^{\circ}$ 4, pp. 777-790.

Igartua, Juan José; Muñiz, Carlos; Otero, José Antonio y De la Fuente, Montse (2007), "El tratamiento informativo de la inmigración en los medios de comunicación españoles. Un análisis de contenido desde la Teoría del Framing", Estudios sobre el Mensaje Periodistico, vol. 13, pp. 91-110.

Núñez, Manuel (2011), "La ética en el periodismo multimedia actual", Perspectivas de la comunicación, vol. 4, $\mathrm{n}^{\circ}$ 1, pp. 166-171.

Ordaz, Pablo (2013a), “«Permaneceré escondido para el mundo»”, El País, 15 de febrero.

Ordaz, Pablo (2013b), “El Papa alerta contra la corrupción”, El País, 24 de febrero, p. 2. 
Ordaz, Pablo (2013c), "El Papa renuncia acosado por la enfermedad y las intrigas", El País, 12 de febrero, pp. 2-3.

Ordaz, Pablo (2013d), "Viejo y cansado, pero no enfermo", El País, 13 de febrero, p. 3.

Ordaz, Pablo (2013e), "El último Ángelus llama a la oración”, El País, 25 de febrero, p. 5.

Ordaz, Pablo (2013f), "Los escándalos ensombrecen el cónclave”, El País, 22 de febrero, p. 2.

Ordaz, Pablo (2013g), "Benedicto XVI llama a la unidad y a «superar las rivalidades» en la Iglesia”, El País, 14 de febrero, p. 4.

Ordaz, Pablo (2013h), “«Las aguas bajaban agitadas y Dios parecía como dormido»", El País, 28 de febrero, p. 4.

Ordeix, Enric y Lazuela, Ferrán (2013), “¿Quién consiguió más liderazgo de opinión en la consagración de la Sagrada Familia, el Papa o el Templo?”, Estudios sobre el Mensaje Periodístico, vol. 19, $\mathrm{n}^{\circ}$ 1, pp. 351-359.

Örnebring, Henrik (2013), "Anything you can do, I can do better? Professional Journalists on Citizen Journalism in Six European Countries", International Communication Gazette, vol. 75, n 1, pp. 35-53.

Painter-Morland, Mollie y Deslandes, Ghislain (2017), "Reconceptualizing CSR in the Media Industry as Relational Accountability", Fournal of Business Ethics, vol. 143, n ${ }^{\circ}$ 4, pp. 665-679.

Parés-Maicas, Manuel (1995), "The Ethics of Political Communication”, European Fournal of Communication, vol. 10, $\mathrm{n}^{\circ}$ 4, pp.475-495.

Pence, Harry E. (2015), "Will Big Data Mean the End of Privacy", Fournal of Educational Technology Systems, vol. 44, n 2, pp. 253-267.

Pérez-Latre, Francisco Javier (2019), "Los medios, los papas y la comunicación del Vaticano entre Benedicto XVI y Francisco (2007-2017)”, Church, Communication and Culture, vol. 4, $\mathrm{n}^{\circ}$ 1, pp. 61-78.

Phillips, Angela (2010), "Transparency and the New Ethics of Journalism”, Fournalism Practice, vol. 4, nº 3, pp. 373-382.

Pou Amérigo, María José (1998), "La Conferencia Episcopal como noticia: Análisis de la instrucción pastoral 'La verdad os hará libres' a través del diario El País” (Universidad Complutense de Madrid). Tesis Doctoral. 
Pou Amérigo, María José (2006), "Conclave y apagon informativo: Informacion y especulacion en la eleccion de Benedicto XVI", Estudios sobre el Mensaje Periodistico, vol. 12, pp. 195-218.

Pou Amérigo, María José (2008), "El hecho religioso y su tratamiento periodístico: limitaciones y dificultades", Estudios sobre el Mensaje Periodistico, vol.14, pp. 561-573.

Pou Amérigo, María José (2009), "La importancia del especialista en la gestión periodística del conflicto. El caso de la polémica de Ratisbona”, en Fernández Sanz, Juan José; Sanz Establés, Carlos y Rubio Moraga, Angel L., Prensa y periodismo especializado IV, Editores del Henares, Guadalajara, pp. 101102.

Repiso, Rafael; Rodríguez-Pinto, Miguel Ángel y García García, Francisco (2013), "Posicionamiento y agrupación de la prensa española: análisis de contenido de las noticias generadas en la Jornada Mundial de la Juventud 2011”, Estudios sobre el Mensaje Periodístico, vol. 19, n 2, pp. 1091-1106.

Restrepo, Javier D. (2001), "La objetividad periodística: utopía y realidad", Chasqui, vol. 74, pp. 10-13.

Richards, Ian (2009), "Stakeholders versus Shareholders: Journalism, Business, and Ethics", Journal of Mass Media Ethics, vol. 19, n 2, pp. 119-129.

Rosenstiel, Tom y McBride, Kelly (eds.) (2013), The New Ethics of Journalism: Principles for the 21st Century, SAGE, Los Ángeles.

Sahuquillo, María R. (2013), "Benedicto XVI ha luchado para poner fin a la impunidad de los pederastas", El País, 12 de febrero, p. 13.

San Martín, Raquel (2008), "Against the Objectivity. The Journalistic Neutrality Myth and the Alternatives to the Rethought it", Perspectivas de la Comunicación, vol. 1, pp. 73-80.

Sanders, Karen (2003), "El periodismo y la ética: un análisis desde la perspectiva de la ética de la virtud", Empresa y Humanismo, vol. 6, n 2, pp. 403-438.

Santín, Marina (2012), "La construcción de la agenda informativa y la ética profesional en la prensa: espacios de desencuentro", Telos. Cuadernos de Comunicación e Innovación, vol. 90, pp. 36-42.

Santos, María Teresa y Pérez Dasilva, Jesús (2020), "La presencia de informaciones relacionadas con la religión católica en la prensa española”, Obets. Revista de Ciencias Sociales, vol. 15, nº 1, pp. 285-316. 
Serrano, José Francisco (2004), "Información religiosa especializada" en Fernández del Moral, Javier (ed.) Periodismo especializado, Ariel, Barcelona, pp. 397-418.

Singer, Jane B. (2008), "The Journalist in the Network. A Shifting Rationale for the Gatekeeping Role and the Objectivity Norm", Tripodos, vol. 23, pp. 61-76.

Sierra, Javier; Muñoz, Pablo y Liberal, Sheila (2013), "El impacto de la renuncia al pontificado de Benedicto XVI en la prensa generalista de carácter nacional. El día después", Sphera Publica, vol. 13, n 1, pp. 19-37.

Sinova, Justino (2003), “Acerca de la responsabilidad pública del periodista. La verdad, los derechos de los públicos y otras exigencias éticas del trabajo informativo", Doxa Comunicación, vol. 1, pp. 171-184.

Sjøvaag, Helle y Krumsvik, Arne H. (2018), "In Search of Journalism Funding", fournalism Practice, vol. 12, no 9, pp. 1201-1219.

Soria, Carlos (1991), La hora de la ética informativa, Mitre, Barcelona.

Stern, Reuben J. (2008), "Stakeholder Theory and Media Management: Ethical Framework for News Company Executives", Fournal of Mass Media Ethics, vol. 23, n ${ }^{\circ}$ 1, pp. 51-65.

Tobella, Alba y González Vejo, Susana (2013), “El Papa pone los pies en la tierra", El Pais, 13 de febrero, p. 8.

Trevino, Linda K; Weaver, Gary R; Gibson, David G. y Toffler, Barbara L. (1999), "Managing Ethics and Legal Compliance: Whatworks and What Hurts", California Management Review, vol. 41, n² 2, pp. 131-151.

Tremblay, Gaëtan (2014), "El espacio de los servicios públicos de comunicación en las sociedades del conocimiento", RAE-IC Revista de la Asociación Española de Investigación de la Comunicación, vol. 1, n 1 , pp. 1-10.

Urban, Juliane y Schweiger, Wolfgang (2014), "News Quality from the Recipient's Perspective”, fournalism Studies, vol. 15, nº 6, pp. 821-840.

Van der Wurff, Richard y Shoenbach, Klaus (2014), "Civic and Citizen Demands of News Media and Journalists: What does the Audience Expect from Good Journalism?", Fournalism \& Mass Communication Quarterly, vol. 9, $\mathrm{n}^{\mathrm{o}} 3$, pp. 433-451.

Vicente Mariño, Miguel y López Rabadán, Pablo (2009), "Resultados actuales de la investigación sobre framing: sólido avance internacional y arranque 
de la especialidad en España”, ZER. Revista de estudios de comunicación, vol. 26, $n^{\circ} 14$, pp. 13-34.

Wahl-Jorgensen, Karin (2007), Fournalists and the Public: Newsroom Culture, Letters to the Editor and Democracy, Hampton Press, Creskill, NJ.

Ward, Stephen J.A. (2010), Global fournalism Ethics, McGill-Queen’s University Press, Montreal \& Kingston London, Ithaca.

Warren, Richard C. (1993), "Codes of Ethics, Bricks without Straw”, Business Ethics: A European Review, vol. 4, n² 2, pp. 187-191.

Weber, Max (1993), El político y el científico, Alianza, Madrid.

Weber, James y Wasieleski, David (2013), “Does Job Function Influence Ethical Reasoning? An Adapted Wason Task Application", Fournal of Business Ethics, vol. 85, pp. 187-199.

Webley, Simon y Werner, Andrea (2008), "Corporate Codes of Ethics: Necessary but not Sufficient", Business Ethics: A European Review, vol. 17, $\mathrm{n}^{\circ}$ 4, pp. 405-415.

Youm, Ho-Youm y Park, Ahran (2016), "The "Right to be Forgotten" in European Union law: Data Protection Balanced with Free Speech?", fournalism y Mass Communication Quarterly, vol. 93, nº 2, pp. 273-295. 
